\title{
Automatic Generation Control Operation with Electric Vehicles
}

\author{
P. M. Rocha Almeida \\ J. A. Peças Lopes \\ jpl@fe.up.pt \\ F. J. Soares \\ pedro.almeida@fe.up.pt \\ filipe.soares@fe.up.pt \\ M. H. Vasconcelos \\ mhv@fe.up.pt \\ Instituto de Engenharia de Sistemas e Computadores do Porto (INESC Porto) and Faculdade de Engenharia da \\ Universidade do Porto (FEUP), Porto, Portugal
}

\begin{abstract}
This paper presents a methodology to make EV able to contribute to secondary frequency regulation, by participating in Automatic Generation Control (AGC). The aggregator entity is used in this methodology to act as intermediate between the AGC and the EV controllers. The case-study used is an approximation of the Portuguese transmission/generation network, including existing tie lines with Spain, to which a solid three-phase short circuit was applied. After the disturbance, the impact of EV in the AGC operation was studied for two different situations: $\mathrm{EV}$ contributing to secondary frequency regulation and EV behaving as uncontrollable loads. The results obtained for both situations were then compared, in terms of interconnection active power flows in the existing tie-lines and its re-establishment time.
\end{abstract}

\section{INTRODUCTION}

The growing concerns with environmental issues are leading policy makers across the world to seek and implement measures in order to decrease pollutants emissions to the atmosphere. The transportation sector, which accounts for over than half of the total world's oil consumption, is naturally one of the core areas where urges to implement ground-breaking actions to reduce its impact over the environment. One of the most effective measures to accomplish such a target is to replace current vehicles for new ones running on other "cleaner" energy sources, like hydrogen or electricity. While hydrogen vehicles are still facing some problems like safety issues and the low efficiency, battery Electric Vehicles (EV) seem to be ready to be launched in the markets and to replace the conventional cars, at least for medium / short distance journeys [1].

Large scale deployment of EV connection to electricity grids, for charging purposes, will undoubtedly increase the energy consumption and induce several changes on the networks management and operation.

In a steady-state basis, several studies aiming to evaluate EV impacts on electricity grids have already been developed. As an example, in [2] it is shown that grid restrictions may limit the growth of EV penetration, if no additional measures are adopted. The same study also present several solutions for that problem, all of them focused on the management of EV batteries, either in a direct or indirect way.

Regarding dynamic issues, in [3] it is shown that EV can be used to improve islanded systems dynamic behaviour by exploiting either their controllability, due to their charging flexibility, or the possibility of injecting power, exploiting their storage capabilities. In the work developed in [4], the possible contributions that EV may provide to fast primary power/frequency control are described, when acting either as a highly flexible and controllable load and/or as an energy storage device.

The work developed in this paper intends to broaden the fields of application of the Vehicle-to-Grid related concepts, by designing a method to have EV participating in Automatic Generation Control (AGC), contributing in this way to secondary frequency regulation. To accomplish this objective, some modifications were introduced in a conventional AGC system in order to make possible the regulation of $\mathrm{EV}$ power consumption/output in response to changes in system frequency and in the tie-lines interchange scheduling.

To simplify the communication process between the AGC and $\mathrm{EV}$, several EV aggregation entities were assumed to be available $[4,5]$. These aggregators' main functionality is the grouping of EV, according to their owners' willingness, so that together they represent a virtual large storage plant with an adequate size to assist the AGC in the system's secondary frequency control.

When a disturbance occurs in the system, the AGC will order the EV to change their power consumption/output by sending set-points to the aggregators under its domain that, by their turn, will distribute these set points among the EV connected to the grid at that time.

\section{AGC OPERATION}

\section{A. Conventional System}

The AGC is a key element for the secondary frequency control. Being a centralized and automatic control unit in continuous operation, it maintains a balance between 
generation and consumption within each control area as well as the system frequency within the synchronous area. It takes into account the control program without impairing the primary control that is operated in the synchronous area autonomously.

The AGC modifies the active power set-points of generators and should, according to the UCTE, reestablish the interconnection values within 15 minutes after an incident. Adequate secondary control depends on generation resources made available by generation companies to the TSO, independently from primary control reserves [6].

\section{B. AGC Operation with EV}

Regarding secondary frequency control with EV, some modifications, presented in Fig. 1, need to be introduced in conventional AGC systems, in order to make the regulation of EV power consumption/output possible in response to deviations of system frequency, $f_{i}$, in relation to its reference, $f_{\text {REF }}$, and of the tie-lines active power flow, $\mathrm{Pif}_{\mathrm{i}}$, in relation to the interchanges scheduling, $\mathrm{Pif}_{\mathrm{REF}}$. As in the conventional AGC, B is the frequency bias that measures the importance of correcting the frequency error, when compared with the correction of the interchange power error; $\mathrm{k}_{\mathrm{i}}$ is the gain of the integral controller; $\mathrm{Pe}_{\mathrm{m}}^{\mathrm{ini}}$ is the current dispatch for machine $\mathrm{m}$, $\mathrm{fP}_{\mathrm{m}}$ its participation factor and $\operatorname{Pref}_{\mathrm{m}}$ its new active power set-point value. $\mathrm{Pa}_{\mathrm{k}}^{\text {ini }}$ is the current load of $\mathrm{EV}$ aggregator $\mathrm{k}$ (entity whose importance will be further developed in this section) and $\mathrm{fP}_{\mathrm{Ak}}$ and $\mathrm{Pref}_{\mathrm{ak}}$ the aggregator $\mathrm{k}$ participation factor and new active power set-point.

These control functionalities to be provided by EV are intended to keep the scheduled system frequency and established interchange with other areas within predefined limits.

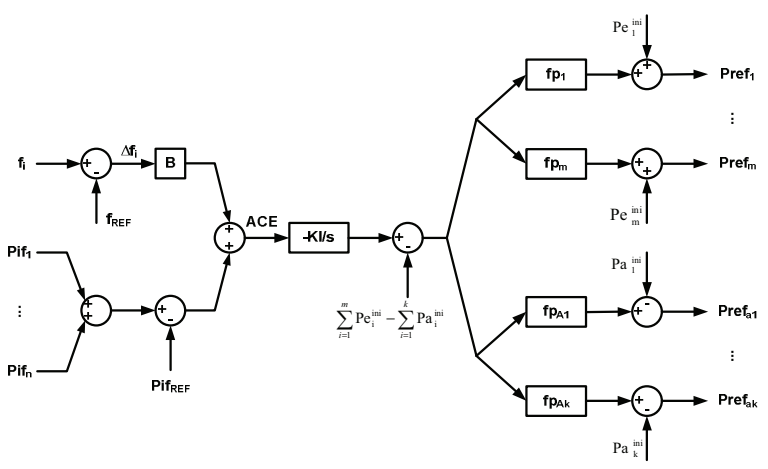

Fig. 1. AGC operation in the presence of EV aggregators.

In order to provide secondary reserves, EV must be an active element within the power system. Typically, reserves market participants would be the transmission company, providing buying bids, and generation companies, selling bids. If EV would enter this market individually their visibility would be small and due to their stochastic behaviour rather unreliable.

Nonetheless, if an aggregating entity exists, with the purpose of grouping $\mathrm{EV}$ to enter in the market negotiations, then reserve quantities would be more significant and the confidence on its availability much more accurate. In this sense, a conceptual framework capable of dealing with EV presence was adopted as depicted in Fig. 2. Beside secondary reserve, EV may provide other ancillary services like primary reserves, voltage control or performing load shifting by adhering to smart charging schemes [1].

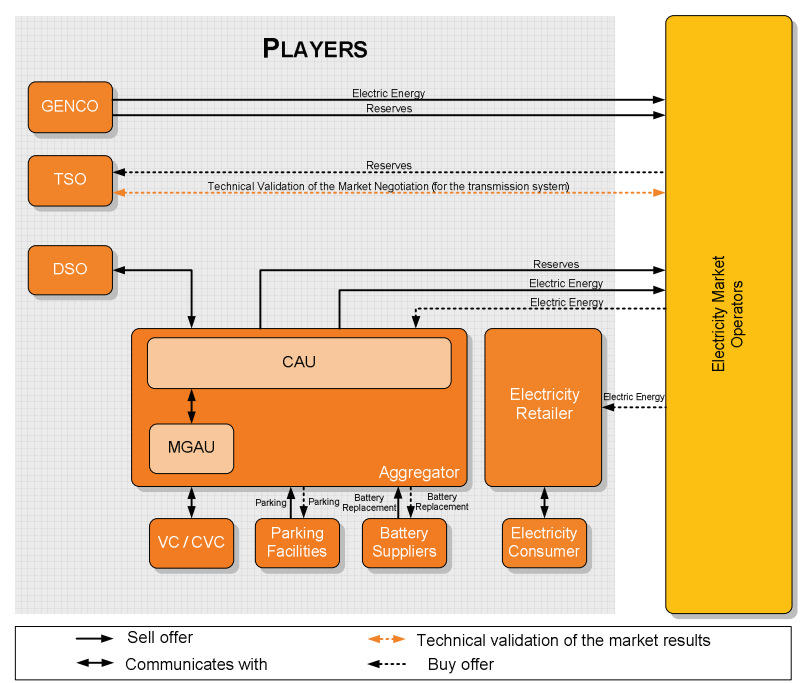

Fig. 2. Conceptual framework for integration EV as active elements within a power system.

As a large EV penetration is expected in the future, an Aggregator can be composed by two types of sub-entities with hierarchical dependence: the Central Aggregation Unit (CAU) and the MicroGrid Aggregation Unit (MGAU). The CAU will be physically connected at the Medium Voltage (MV)/High Voltage (HV) substations and will communicate with the MGAU placed at the MV/Low Voltage (LV) substations. The MGAU will establish the bridge between individual EV at the LV level through a Vehicle Controller (VC) and the CAU, removing complexity in the communication requirements. When fleets of EV have a connection to the MV network they may communicate directly with the CAU through a Cluster of Vehicles Controller (CVC). An Aggregator may have several CAU and each CAU will communicate with several other MGAU, depending on the amount of EV controlled and their geographical dispersion.

In order to define the amount of reserves that the aggregators are available to offer in the electricity markets, they will have to forecast the EV availability to 
provide these services in the next day. This estimative will be done through the analysis of the type of contracts made between aggregators and EV owners. As described in [2], four different contracts are expected to be established between these entities:

- Dumb charging - EV owners are completely free to connect and charge their vehicles whenever they want.

- Multiple prices tariff - electricity is cheaper during some specific hours of the day.

- Smart charging - active management strategy that continuously monitors the grid and in case of technical constraints decreases the consumption level of the EV. It may use real-time pricing.

- Vehicle-to-Grid (V2G) - similar to smart charging, but EV can be regarded not only as a controllable load but also as full storage device that can inject stored energy into the grid.

While in the first two the EV is seen as an uncontrollable load, in the latter two it offers to the aggregators the possibility of controlling the power it absorbs from the grid. In the $\mathrm{V} 2 \mathrm{G}$ contracts the aggregators have even further controllability over EV, since they can also manage the amount of power it injects into the grid. Therefore, for reserves negotiations in the market, aggregators will take into account only the availability of the EV with a smart charging or V2G contract.

When providing secondary control, the Aggregators will receive set-points according to their participation factor and then redistribute it among the participating EV (EV with smart charging or V2G contracts) using the exposed communication infrastructure.

$\mathrm{EV}$ reaction to a new power set-point is almost immediate as the power electronic devices interfacing them with the grid have no inertia as would occur with conventional synchronous machines. Yet, such complex communication channel may introduce a small additional.

\section{III.Case-Study}

The case-study of this work is an approximation of the Portuguese transmission/generation network, as described in [7], including existing tie lines with Spain. With over 7 GW of conventional thermal and $5 \mathrm{GW}$ of hydro power plants, in the Portuguese network there are $3.35 \mathrm{GW}$ of wind power installed [8]. The Spanish system, by its turn, has $15.87 \mathrm{GW}$ of wind power installed [9] and $21 \mathrm{GW}$ conventional thermal, $20 \mathrm{GW}$ hydro and $11 \mathrm{GW}$ nuclear power plants.

The interconnection capacity between the two control areas totalizes $6844 \mathrm{MVA}$ in the winter and $6460 \mathrm{MVA}$ in the summer [10]. However, due to technical constraints both from the generation and transmission systems, typically Portugal will not export more than $1500 \mathrm{MW}$ or import more than $1400 \mathrm{MW}$.

Fig. 3 depicts the single-line diagram of the considered transmission system with 2 control areas. Control area 1 regards the network from Portugal. In order to model the interconnections with the Spanish system, a dynamic equivalent system was modelled, in control area 2, by considering a single bus bar with four equivalent generators, one for each primary resource. This equivalent bus bar was interconnected to control area 1, through 5 tie lines, all of them with a voltage level of $400 \mathrm{kV}$.

In area 1 there is also a generator equivalents per technology at each substation node that composes the transmission network and the Portuguese transmission grid is explored in three main voltage levels: $150 \mathrm{kV}$ (marked in blue in Fig. 2), $220 \mathrm{kV}$ (green) and $400 \mathrm{kV}$ (red). Each control area has its own AGC unit controlling frequency and also the power flowing in the interconnections. In this case there are five tie lines, all of them with a voltage level of $400 \mathrm{kV}$.

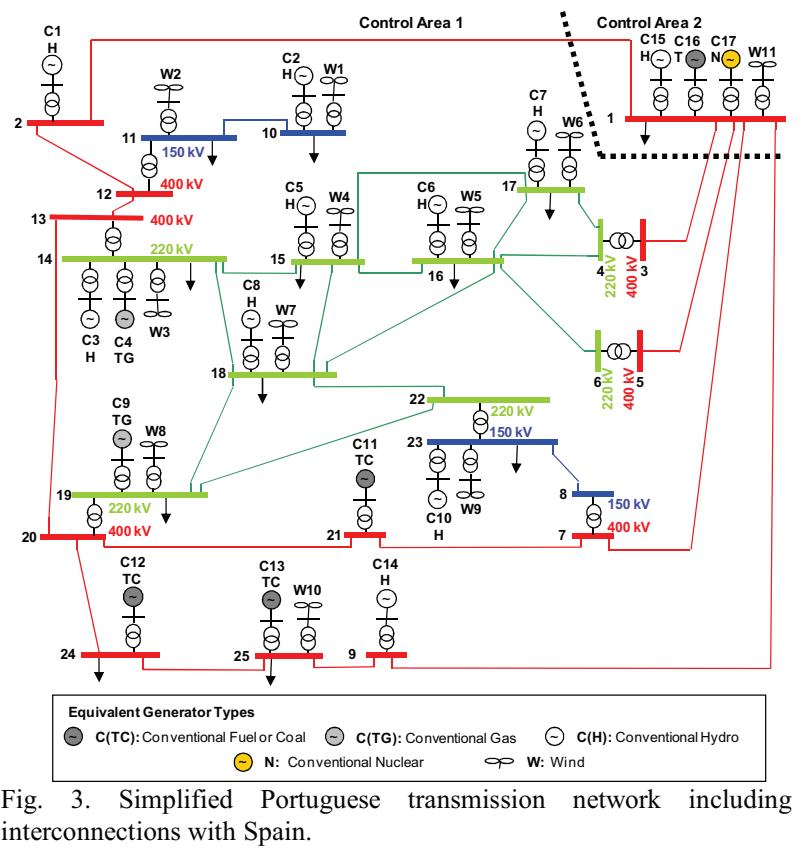

Each conventional generator was modelled by a $4^{\text {th }}$ order model synchronous machine and the corresponding block diagram is depicted in Fig. 4. Each generator has a frequency proportional control gain that reflects each machine droop (R), a governor model, ramping limitation, mechanical power limits, a turbine model and a synchronous generator. An active power reference signal sent by the AGC is added to the droop control action. Thermal generation units were equipped with a simple governor, with a time constant Tg delay, and a three stage thermal turbine with reheat. Hydro units were furnished 
with a similar governor but with transient droop compensation and a typical hydro turbine (with water starting time). These models are commonly known from the literature and can be found in [11]. To every conventional unit an IEEE type 1 voltage regulator was assumed.

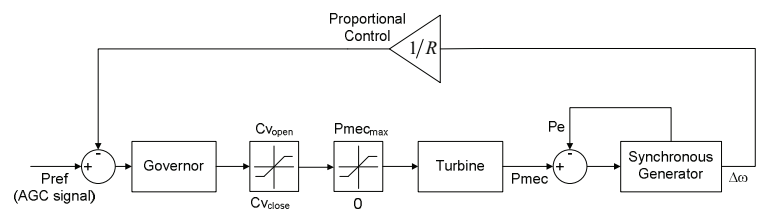

Fig. 4. Model of the synchronous machine.

For the wind generators equivalents a $3^{\text {rd }}$ order model was adopted for squirrel cage simple induction machine. This option leads to a worst case scenario as presently wind generators installed in Portugal are of three different types: doubly fed induction generators, variable speed synchronous generators, electronically interfaced with the grid, or simple induction generators. In fact, legislation in Portugal imposes specific requirements for grid connection of new wind parks since 2005, [12], being one of these requirements the Fault Ride-Through (FRT) capability. In the analyzed case-study, the undervoltage relay associated to each wind generator without fault ride through capability was set to 0.9 p.u.

\section{IV.Scenario Characterization}

\section{A. Methodology}

This study has been conducted over the interconnected Portuguese system. The chosen scenario was a valley hour during the winter (6 a.m.) where there was high availability of hydro and wind resources. In such conditions there is a limited value of reserve available and if a large disturbance occurs severe consequences may affect the security of operation of the power system. Table I presents the initial load, dispatch and wind power production.

For this study the total load resulting from the EV battery charging in Portugal, presented in Table I as $\mathrm{P}_{\mathrm{EV}}$, was obtained assuming that $30 \%$ of the entire Portuguese light vehicle fleet was composed by EV. As in Portugal exists ca. 5 million light vehicles, the number of EV considered in this scenario was roughly 1.5 million EV. It was also assumed the existence of three different EV: plug-in hybrids with a rated power of $1.5 \mathrm{~kW}$ (representing $20 \%$ of the entire EV fleet), a medium EV with $3 \mathrm{~kW}$ and a large EV with $6 \mathrm{~kW}$ (each representing $40 \%$ of the EV fleet).

The $581 \mathrm{MW}$ of EV load were obtained by considering that $10 \%$ of the total number of EV were charging at the hour considered in this simulation. This assumption was taken from the smart charging scenario presented in Fig. 5 and obtained from [2]. For this scenario, at the considered hour, the percentage of EV charging is roughly $10 \%$ of the total, as shown in Fig. 5.
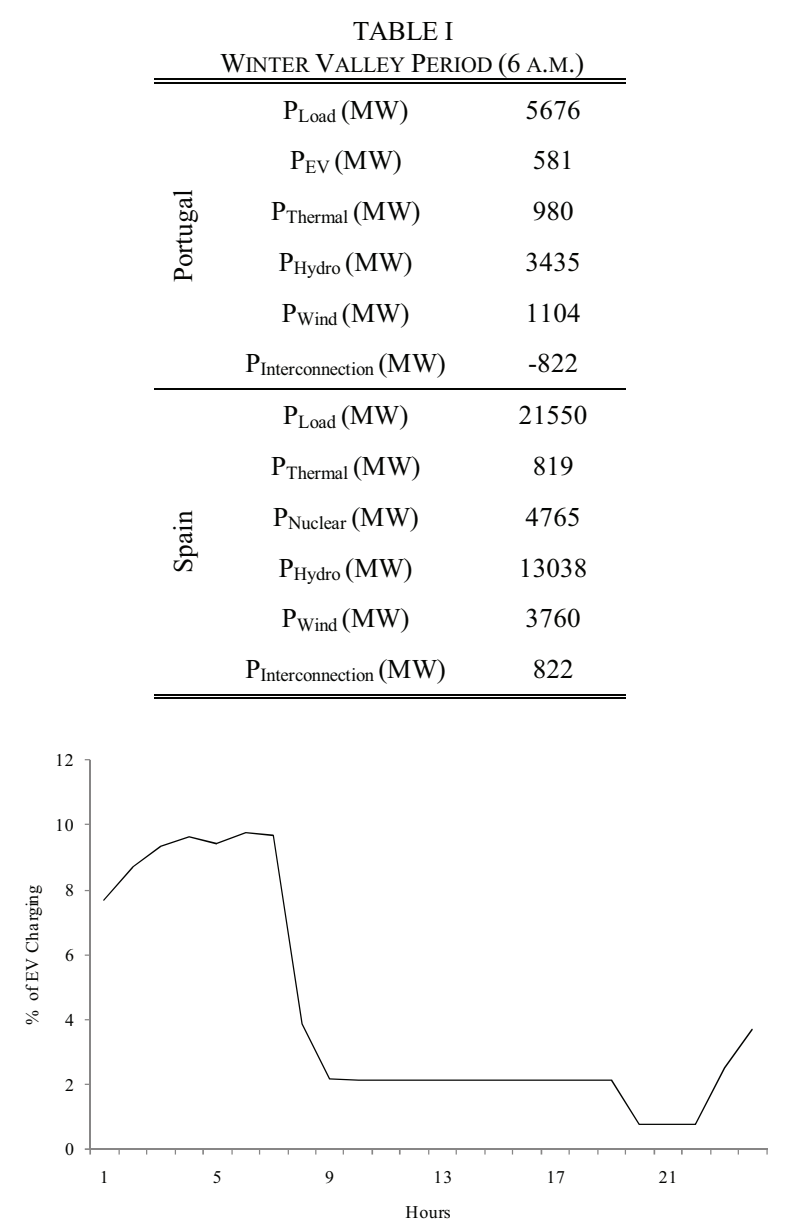

Fig. 5. Percentage of EV charging during a typical day, under a smart charging strategy [2].

The dynamic simulations were performed with the Plansys software, a conventional step-by-step numerical simulation tool used to perform dynamic simulation of power systems, developed at INESC Porto.

The 1.5 million EV were modelled as aggregated controllable load devices, connected in different high voltage substations, assuming that the aggregator concept described before was available. The impact evaluation of the controllable EV interface devices is performed by analyzing the dynamic behaviour of the system following a large disturbance. A similar scenario to the recent episode that occurred in the 15th of November 2009 in Portugal was adopted, i.e. the loss of approximately 1300 MW of wind power production following a short circuit in the grid. Each EV that was charging at that specific 
moment is able to provide secondary reserve by reducing its load until it reaches zero consumption. No V2G usage was tested in this work.

The impact of EV in the AGC operation in bulk power systems is studied by performing two different type studies:

1) $\mathrm{EV}$ are not used for AGC operation following the previously described disturbance.

2) EV are obtaining active power set-points from the AGC, through the aggregation units, as a response to the same disturbance.

Finally the results of 1) and 2) are compared in terms of maximum interconnection active power deviations in the specified tie-lines and its re-establishment time.

The adopted parameters for the AGC were set according to the requirements and recommendations of UCTE. More specifically, for the bias parameter, B, a constant value was adopted, being higher than the expected control area stiffness value for next year peak load (in order to accentuate the effect of primary control and not counteract it). Moreover, a delay on the communication channel was introduced with the value of 2 seconds.

The participation factors for each group providing secondary control were set regarding the different primary resources. Hydro units were given a participation factor ten times higher than thermal units and ten times lower than EV. When the disturbance is eliminated and the system re-established with regained security of supply, then EV participation factors should be gradually reduced, in order to enable EV to continue charging their batteries as before. This period is not analysed in this work as it is does not pose any really demanding operating problems. It is just related with the gradual redefinition of participation factors during normal grid operation.

\section{B. Security Assessment}

The applied disturbance consists on a solid three-phase short circuit on the closest extremity to bus 15 of one of two identical parallel lines between buses 15 and 16. Fault clearing occurs $300 \mathrm{~ms}$ after fault inception by removing the faulty line from service.

As mentioned before, wind generators undervoltage relays will operate if voltage at their connection buses falls below the defined threshold. Due to the described event, in this case there is a loss of $1104 \mathrm{MW}$ of wind power production.

According to the UCTE security definitions, each country must guarantee security of operation up to the loss of generation with the value of the largest available unit through the tertiary reserve. However, it defines secondary reserve by an empirical rule that, in Portugal, makes its value vary between $140 \mathrm{MW}$ and $190 \mathrm{MW}$. Adding this value to the requirement of $70 \mathrm{MW}$ of primary reserves, it amounts to up to $260 \mathrm{MW}$ of spinning reserve, which is significantly lower than the value of the lost generation.

The immediate system reaction is an increased loading of the tie-lines between Portugal and Spain and, consequently, between Spain and France, as most of the primary control action will be provided by Spain and the other UCTE systems.

Tie-lines maximum limit are defined not only by their own thermal limit but also according to internal technical constraints that the transmission grid of each control area may present (situation that happens rather frequently). Therefore, when interconnection flows change, power flows within each control area are also modified and may result in temporary overloading. Such fact may jeopardize the security of operation of the system.

\section{Results}

As described in the section IV, studies were conducted with and without EV participating in the AGC operation, in order to benchmark EV performance in secondary reserves provision.

When the severe fault occurs, at time $\mathrm{t}=0$, near bus 15 , several wind farms went out of service. This outage requires the action of the primary frequency control to rebalance load and generation. To do so Portuguese conventional generators reacted initially according to their primary control loops. Since the UCTE system is quite strong, frequency deviations are not a matter of concern for a disturbance like this. However, after primary frequency control reaction, most of the power comes from other UCTE systems increasing dramatically the tie-line power flows, as mentioned before, motivating the reaction of the AGC.

As illustrated in Fig. 6, regarding the interchange active power flows in tie-lines, the reaction of secondary control with EV participation is significantly faster than that considering EV non-controllable loads. This situation remains during all the time-frame of AGC operation.

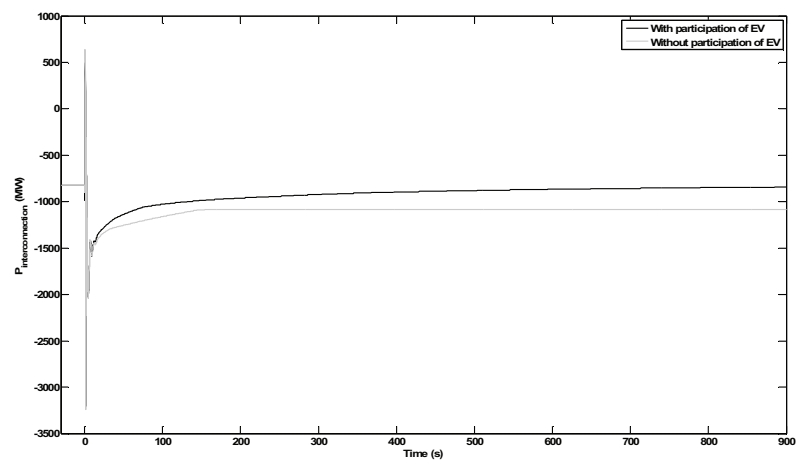

Fig. 6. Interconnection active power flow Portugal-Spain (Portuguese export value). 
The AGC with EV achieves a final value $(t=15$ minutes) for the interchange power flow of $-843 \mathrm{MW}$ as opposed to the $-1082 \mathrm{MW}$ in the other scenario. For both case the pre-disturbance value was $-822 \mathrm{MW}$, meaning that Portugal was importing electrical energy from Spain. Yet, both values (with and without EV participation in secondary control) are within the limits for interconnection exchange during valley winter periods.

Tables II and III present the used reserve level with and without $\mathrm{EV}$ participating in the AGC operation. As can be observed, for $\mathrm{t}=2$ minutes there is already an advantage of the AGC with EV greater than $100 \mathrm{MW}$. Another issue deals with the available reserve level. Without EV the total reserve levels considered in this study would be insufficient to re-establish the initial interconnection value, whereas the extra reserve provided by EV enables that possibility.

TABLE II

RESERVE USED WITHOUT EV PARTICIPATING IN SECONDARY CONTROL

\begin{tabular}{cccc}
\hline \hline & & \multicolumn{2}{c}{ Used Reserve (MW) } \\
\cline { 3 - 4 } & Reserve (MW) & $\mathrm{t}=2 \mathrm{~min}$ & $\mathrm{t}=15 \mathrm{~min}$ \\
\hline Hydro & 461 & 461 & 461 \\
Thermal & 590 & 211 & 256 \\
EV & 0 & 0 & 0 \\
\hline Total & 1049 & 672 & 717 \\
\hline \hline
\end{tabular}

TABLE III

RESERVE USED WITH EV PARTICIPATING IN SECONDARY CONTROL

\begin{tabular}{cccc}
\hline \hline & & \multicolumn{2}{c}{ Used Reserve (MW) } \\
\cline { 3 - 4 } & Reserve (MW) & $\mathrm{t}=2 \mathrm{~min}$ & $\mathrm{t}=15 \mathrm{~min}$ \\
\hline Hydro & 461 & 192 & 316 \\
Thermal & 590 & 31 & 74 \\
EV & 581 & 581 & 581 \\
\hline Total & 1630 & 804 & 971 \\
\hline \hline
\end{tabular}

With or without the action of EV within the secondary reserve delivery, frequency was re-established during the first 20 seconds. As expected, due to the large value of the frequency bias parameter, the maximum transient deviation assumes more or less the same value, as it is visible in Fig. 7.

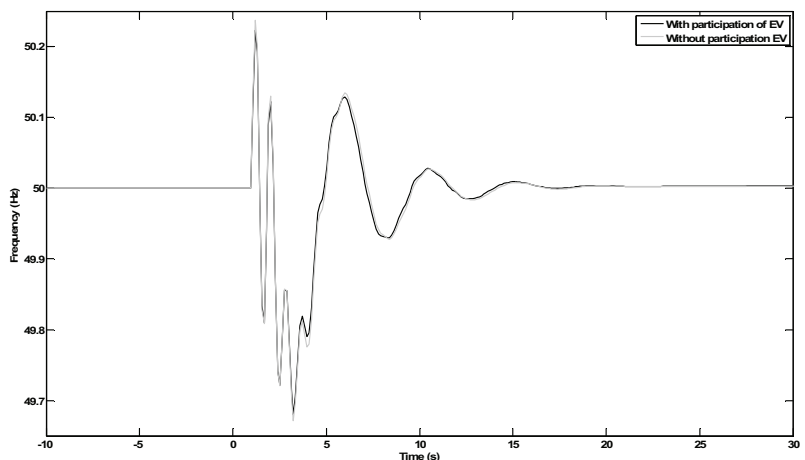

Fig. 7. Frequency evolution.

Another potentially beneficial effect regards power flows inside control area 1. When EV participate in AGC operation, there is a faster reduction in the value of line loading after the disturbance. To illustrate this effect, the temporal electrical current evolution, during the first 2 minutes, in lines between buses 16 and 18 and 20 and 21 is presented in Fig. 8 and Fig. 9. Namely, as a result of the EV load reduction, the electrical current in line 20-21 achieves an even lower value than the pre-disturbance one.

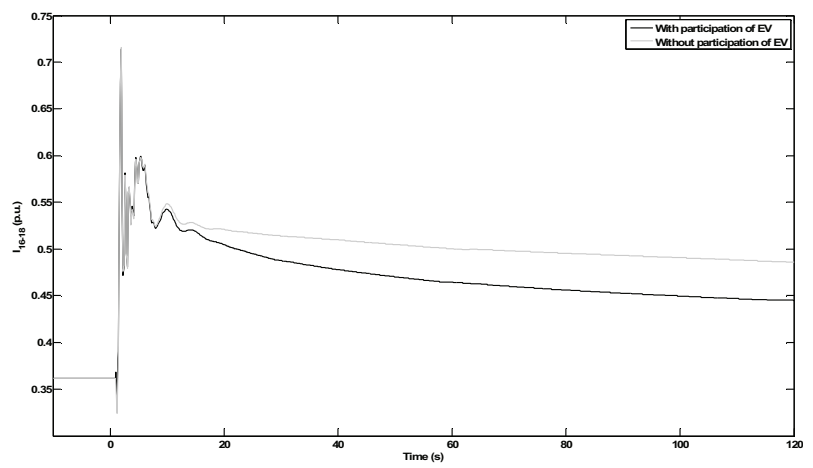

Fig. 8. Electrical current in the line between buses 16 and 18 .

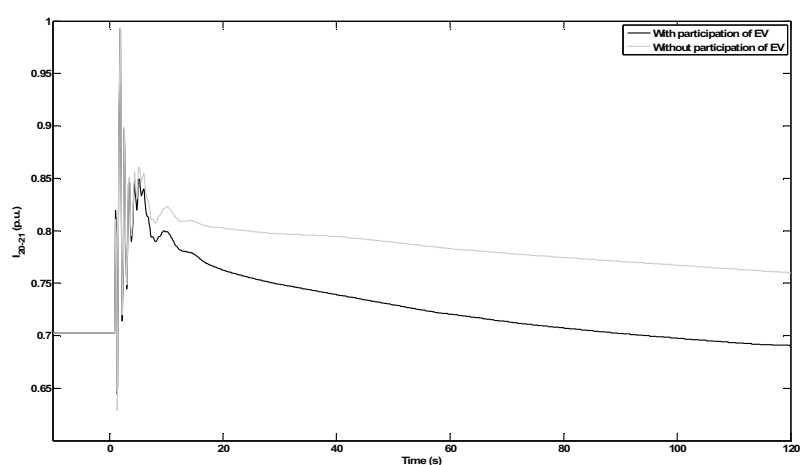

Fig. 9. Electrical current in the line between buses 20 and 21 .

Finally, Fig. 10 depicts the evolution of the Area Control Error (ACE) of area 1, which provides at each 
time step a weighed measure of the deviation of both frequency and tie-line exchange.

From Fig. 10, it is possible to observe that with the participation of EV the ACE assumes values very close to zero from moment $t=10$ minutes. Thus, it was verified that EV really improve the system dynamic behaviour, granting more resilience to the system.

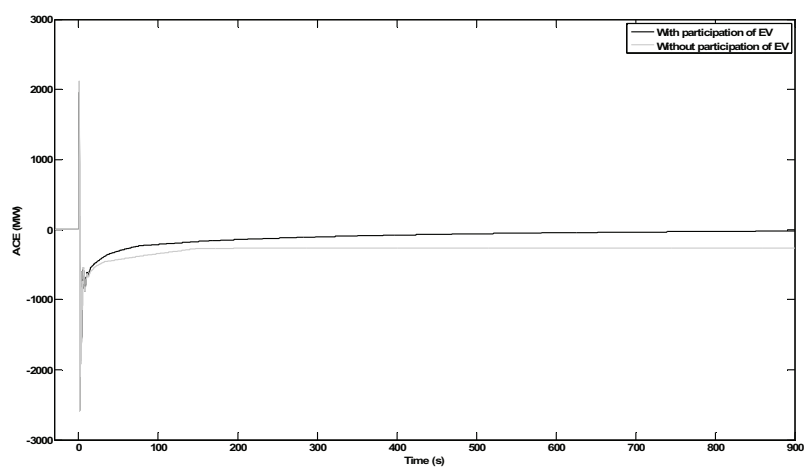

Fig. 10. Area control error for area 1.

\section{Conclusions}

The work developed in this paper establishes a comparison between the electric power system behaviour to a given disturbance with normal AGC operation and with an innovative AGC control that includes $\mathrm{EV}$ participating in secondary frequency control.

There are three main conclusions that can be drawn from this research:

1. Improvement of the system robustness of operation;

2. Increase of the system reserve levels that can be effectively mobilised for secondary control use;

3. Increase safe integration of renewable power sources in the system.

In fact, the fast reaction of $\mathrm{EV}$ power electronic interfaces, together with a communication infrastructure and a control architecture capable to fast communicate the set points from AGC - Aggregators - EV, allows fast and effective corrections of the tie-lines power flows following system loss of generation in one control area.

In previous researches [3], the authors had concluded that large deployment of EV would improve Intermittent Renewable Energy Sources (IRES) integration in isolated systems,. This work proves that when having EV participating in secondary frequency control, it will also enable further integration of IRES in interconnected grids.

Concluding, additional economical and environmental benefits are expected from the adoption of EV smart control strategies, mainly due to avoided start-up of expensive and highly pollutant generation units that compose the tertiary control. As a counterpart EV owners must be properly remunerated when participating in the provision of this type of ancillary services in order to make this concept efficient and with sufficient adherence. This subject should be further researched in future works.

\section{Acknowledgements}

This work was supported in part by Fundação para a Ciência e Tecnologia under Grants SFRH/BD/48491/2008 and SFRH/BD/47973/2008, by Fundo de Apoio à Inovação (Ministério da Economia, da Inovação e do Desenvolvimento), within the framework of the Project REIVE - Redes Eléctricas Inteligentes com Veículos Eléctricos, and by the European Commission within the framework of the European Project MERGE - Mobile Energy Resources in Grids of Electricity, Grant Agreement 241399.

\section{References}

[1] W. Kempton, J. Tomic, "Vehicle-to-grid power fundamentals: Calculating capacity and net revenue", Journal of Power Sources, vol. 144, no. 1, pp. 268-279, June 2005.

[2] J. A. Peças Lopes, F. J. Soares, P. M. Rocha Almeida, "Identifying Management Procedures to Deal with Connection of Electric Vehicles in the Grid", PowerTech2009 - PowerTech 2009, Bucharest, Romania, June, 2009.

[3] J. A. Peças Lopes, P. M. Rocha Almeida, F. J. Soares, "Using Vehicle-to-Grid to Maximize the Integration of Intermittent Renewable Energy Resources in Islanded Electric Grids", ICCEP 2009 - International Conference On Clean Electrical Power Renewable Energy Resources Impact, Capri, Italy, June, 2009.

[4] J. A. Peças Lopes, P. M. Rocha Almeida, F. J. Soares, C. L. Moreira," Electric Vehicles in Isolated Power Systems: Conceptual Framework and Contributions to Improve the Grid Resilience", to be presented at the Conference on control Methodologies and Technology for Energy Efficiency 2010, Vilamoura, Portugal, March, 2010.

[5] C. Guille and G. Gross, "A conceptual framework for the vehicleto-grid (V2G) implementation," Energy Policy, vol. 37, no. 11, pp. 4379-4390, November 2009.

[6] European Network of Transmission System Operators for Electricity - ENTSO-E, "UCTE Operation Hanbook", March 2009.

[7] Helena Vasconcelos, J. A. Peças Lopes, "On-line Functions for Security Operation of Interconnected Systems having Large Wind Power Production", 7th International Workshop on Large-Scale Integration of Wind Power into Power Systems, Madrid, Spain, May 26-27, 2008.

[8] Redes Energéticas Nacionais - REN, "Dados Técnicos 2009", January, 2010.

[9] Red Eléctrica de España - REE, "El sistema eléctrico español", July 2009.

[10] Redes Energéticas Nacionais - REN, "Caracterização das Interligações em 31 de Dezembro de 2008", March 2009.

[11] Prabha Kundur, "Power System Stability and Control", EPRI Power System Engineering Series, McGraw Hill, 1994.

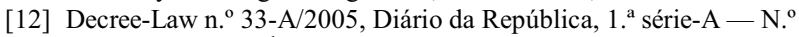
33 - February $16^{\text {th }}, 2007$. 